\title{
Great Effort, Some Concern. \\ How Making Effort to Acquire Information Influences Managerial Reporting
}

\begin{abstract}
I investigate if managers' tendency to report opportunistically depends on the effort they expend in acquiring the information they need to report. I develop and test theory positing that expending effort to acquire information can justify opportunistic behavior but also enhances a sense of responsibility discouraging unethical actions. I predict that the dominant effect depends on whether the reporting environment induces sufficient concerns for honesty. In my $2 \times 2$ experiment, managers are either endowed with information to report or required to expend intellectual effort to earn it. I also manipulate whether concerns about honesty are triggered by framing reporting in terms of profit allocation or an ethical dilemma. I find that when honesty is not triggered, managers report earned information more opportunistically than endowed information. However, when the reporting context triggers honesty concerns, the negative effect of earned information on opportunistic reporting is alleviated. These results have strong implications for theory and practice by showing the conditions under which acquiring information detrimentally affects reporting behavior.
\end{abstract}

Keywords: information acquisition, opportunistic reporting, other-regarding preferences, honesty, budgeting, slack, effort, experiment 


\section{Introduction}

Acquiring and reporting information are crucial aspects of managers' jobs (e.g., Bruns and McKinnon 1993; Church et al. 2014). For example, managers gather information about local markets and production processes to inform upper management's marketing, production, and capital budgeting decisions (Evans et al. 2001). Although the accounting literature acknowledges the importance of both acquiring and reporting information, it often treats these managerial tasks as distinct responsibilities (e.g., Brown et al. 2009; Schneider et al. 2015). However, the duties are logically linked and could potentially affect each other. In this paper, I investigate whether the process of acquiring information influences managers' reporting of it.

In particular, I develop and test theory suggesting that making an effort to acquire information can influence opportunistic reporting of it. Although managers are often in the best position to acquire information about particular aspects of an organization (e.g., because they spend a lot of time with local markets, customers, and production processes and are in close proximity to them), the ease with which they can obtain this information varies widely in practice (e.g., Huber 1991; Inkpen 2000; Li et al. 2010; Smith et al. 2016). Obtaining information can sometimes be quite effortful, requiring multiple analyses or synthesis from numerous sources, but other times, it can be gained more easily. ${ }^{1}$

Since managers' objectives are not always aligned with those of the parties to whom they report, they regularly have incentives to report information in an opportunistic way and benefit at the expense of another party (e.g., Evans et al. 2001; Caskey et al. 2010). The behavioral literature identifies two variables that can mitigate opportunistic reporting: other-

\footnotetext{
${ }^{1}$ Various factors can determine whether information acquisition requires more or less effort, such as the type and format of the requested information, the organizational environment, technology, and the expertise and experience of the knowledge acquirer. I do not distinguish between these different causes in this paper, but it is noteworthy that many of them can be influenced by organizations (e.g., the format of the requested information, technology).
} 
regarding preferences (i.e., preferences over one's own as well as others' payoffs, motivated by factors such as altruism, inequity aversion, and fairness concerns) and honesty preferences (i.e., preferences for making truthful disclosures) (e.g., Luft 1997; Sprinkle 2003; Fehr and Schmidt 2006; Mittendorf 2006; Rankin et al. 2008; Maas and Van Rinsum 2013). The theory I develop and test suggests that effortful acquisition of information decreases the role of other-regarding preferences but enhances the role of honesty in mitigating opportunistic reporting.

On the one hand, I expect individuals to be less likely to exhibit other-regarding preferences if they exert more effort to earn the information they need to report. Because individuals invest time, effort, and skills to gain information, they can more easily justify serving their own interests by reporting opportunistically (Hsee, 1996; Pierce et al. 2001). On the other hand, honesty preferences are likely to have a larger impact when information is acquired in an effortful way because individuals might feel more personally responsible for such information (Nonaka 1994). Increased responsibility can discourage unethical actions (Bandura 1999; Charness 2000; Libby et al. 2018).

I predict that organizational design choices with respect to the decision-making context determine which of the two effects will be dominant. For example, organizations can promote honesty through contextual cues or the framing of the reporting decision (e.g., Rankin et al. 2008; Douthit and Stevens 2015). I expect that contexts that do not trigger sufficient concern for honesty will be associated with more opportunistic reporting with effortful relative to effortless information acquisition, while contexts that trigger sufficient concern for honesty will decrease opportunistic reporting to a larger extent when individuals exert more effort to acquire information.

I examine the effect of information acquisition on opportunistic reporting in a budget reporting context. In my experiment, managers have to implement a project that incurs a cost. 
Only managers learn this cost, and they therefore submit a budget report to the owner. Opportunistic reporting increases (decreases) the monetary payoff for managers (owners). In this experimental setting, I manipulate the acquisition of information (endowed versus earned information) and whether the reporting context induces honesty (no honesty trigger versus honesty trigger).

In the endowed information condition, managers could simply read the project's implementation cost on their computer screen. In the earned information condition, managers had to expend intellectual effort to determine the project's implementation cost. To identify how honesty triggers within the reporting context influence the effect of earned and endowed information on opportunistic reporting, I use the "mode of reporting" manipulation following Rankin et al. (2008), Douthit and Stevens (2015), and Brown et al. (2017). Specifically, I vary whether the report is framed as a mere allocation of profit (no honesty trigger condition) or as an ethical dilemma (honesty trigger condition). In both conditions, opportunistic reporting increases a manager's payoff and decreases an owner's payoff. Hence, to the extent that managers care about owners' payoff, their other-regarding preferences should decrease opportunistic reporting in both reporting context conditions. However, the motivation to report honestly should be more salient when the reporting decision is framed as an ethical dilemma. Thus, in this condition, honesty preferences are important in mitigating opportunistic reporting on top of other-regarding preferences. Accordingly, I capture the effect of other-regarding preferences by studying the no honesty trigger condition and I isolate the incremental effect of honesty preferences by assessing the difference between the conditions that trigger and do not trigger honesty concerns.

Consistent with my predictions, experimental results show that managers report more opportunistically with earned information relative to endowed information when honesty concerns are not triggered. In a comparison of the no honesty trigger to the honesty trigger 
condition, I find that the incremental effect of honesty causes opportunistic reporting to decrease. However, the manner of information acquisition interacts with the reporting context, such that opportunistic reporting decreases to a greater extent with earned information. This outcome indicates that when the reporting context induces honesty concerns, managers take these concerns into account more with earned information. Supplemental analyses provide additional insights into participants' perceptions about what is fair and honest with earned information relative to endowed information. Furthermore, I study the earned information conditions in depth to investigate how characteristics of earning information affect the tendency to report opportunistically.

These results are important for several reasons. First, I contribute to the literature on managerial reporting by considering the fundamental phase of acquiring the information that needs to be reported. I explicitly recognize that managers often have to expend effort to gather relevant information, and I show that this undertaking can affect their reporting behavior. Whether or not the effect is detrimental depends on the organizational context.

As such, my findings also have important implications for practice because an organization can influence other-regarding and honesty triggers. For example, results of my experiment indicate that carefully framing the budget request to induce honesty might be advisable when acquiring information requires a lot of effort. Moreover, organizations have several other means at their disposal to trigger other-regarding and honesty preferences. Potential approaches include changing the span of control (Dierynck 2012), altering the transparency of payoffs (Douthit and Stevens 2015), installing an organizational culture that values honesty (Trevino 1986), and adopting a code of ethics with public certification (Davidson and Stevens 2013). However, these design choices do not come without a cost, and my results may help to identify when investing in such changes is more or less beneficial. For example, in complex business settings in which gaining information requires substantial 
effort, it can be more beneficial to increase the saliency of honesty relative to environments in which information is acquired more easily. As another practical implication, my findings add to recent concerns about the unintended consequences of the use of systems that facilitate knowledge acquisition (e.g., Sutton et al. 2018). My results suggest that the benefits of installing such systems would ultimately depend on organizational design choices with respect to the decision-making context.

Next, the acquisition of information is a crucial aspect of various accounting settings such as auditing, budgeting, financial statements, and taxes (e.g., Balakrishnan 1991; Sansing 1993; Einhorn and Ziv 2007; Nelson and Tayler 2007). Indeed, managers also gather information intended for the audit committee (e.g., Caskey et al. 2010), analysts and investors (e.g., Bens et al. 2012), and tax authorities (e.g., Omer and Yetman 2007). The ease with which relevant information can be acquired varies widely across and within all these settings. Although honesty and other-regarding preference are traditionally studied in managerial accounting settings, they are increasingly receiving attention in these other accounting areas (e.g., Fischbacher and Stefani 2007; Coricelli et al. 2010; de Bruin 2013; Königsgruber and Palan 2015; Hurley and Mayhew 2019). By showing that having to acquire information in an effortful way has opposing effects on honesty and other-regarding preference, I therefore also contribute more generally to a better understanding of information acquisition in accounting systems.

Finally, since reporting can be considered a type of information sharing, I also contribute to the emerging literature on this theme (e.g., Hwang et al. 2009; Bol and Leiby 2015; Haesebrouck et al. 2015, 2018; Tafkov et al. 2017; Berger et al. 2018). Haesebrouck et al. (2015) show that sharing laboriously acquired information is perceived as a particularly costly activity for which the sharers feel that they should be rewarded in return. This interpretation is consistent with the results I find here since individuals believe they deserve a 
higher payoff, and hence report more opportunistically, when they expend more effort to acquire their information. However, I also demonstrate in this study that salient honesty preferences can alleviate the need to be compensated for sharing laboriously acquired information.

In the next section, I discuss the relevant literature and develop the hypotheses. Section 3 presents the experimental design, followed by the results in section 4 . Section 5 provides the conclusion and discussion.

\section{Background and hypotheses development}

In this section, I first briefly summarize earlier literature on both acquiring and reporting information. Next, I connect these two constructs and explain how information acquisition affects reporting behavior in the hypotheses development section.

\section{Background}

\section{Acquiring information to report}

When managers are asked to report information, they have to collect raw data and derive relevant interpretations by editing, correcting, analyzing, and summarizing the material (Davenport and Prusak 1998; Schneider et al. 2015). During this process, they frequently rely on observations, personal contacts, and informal reports (Bruns and McKinnon 1993). Although the accounting literature acknowledges the importance of the information acquisition task (e.g., Ewusi-Mensah 1981; Schneider et al. 2015), it only briefly recognizes that how individuals acquire their information might influence how they act upon

it. Indeed, not only the information per se, but also the process of acquiring it can affect subsequent behavior or decision making. For example, Nelson and Tayler (2007) investigate whether making users of financial statements perform a transformational analysis themselves rather than simply providing them with the results of such an analysis affects their judgments. The authors find that having to acquire results in an effortful way affects judgments to a 
greater extent because it increases individuals' perception of how well they are informed. Since managers that make reporting decisions differ in many respects (e.g., incentives and responsibilities) from financial statement users that make judgment decisions, investigating the effect of effortful information acquisition on managerial reporting is worthwhile.

Within the context of managerial reporting, the tasks of acquiring and reporting information are logically intertwined. Managers are asked to report information because they are typically in the best position to acquire it. Since they spend a lot of time with particular aspects of the organization (e.g., local markets, customers, production processes), they often have the opportunity to acquire superior information about them (Milgrom and Roberts 1992). ${ }^{2}$ Nevertheless, the ease with which they can obtain this information varies widely in practice (e.g., Huber 1991; Inkpen 2000; Li et al. 2010; Smith et al. 2016). Acquiring relevant information can be rather straightforward; however, it might sometimes require substantial effort, for example, when managers have to combine information from a variety of sources or perform several analyses. In addition, recent technological developments influence the effort required to gather information (e.g., Sutton et al. 2018). As I argue below, a higher level of effort to acquire information could have an impact on managers' tendency to report it opportunistically.

In the next section, I discuss the determinants of opportunistic reporting as identified by the behavioral literature.

\section{Determinants of reporting behavior}

Since managers' objectives are not always aligned with those of the parties to whom they report, they may have self-serving incentives to opportunistically report their private information (Webb 2002). For example, managers might report inflated results to an upper

\footnotetext{
${ }^{2}$ Moreover, even if another employee can observe the same information, that person can still lack the expertise or background needed to understand and evaluate it (Ditillo 2004).
} 
manager in order to garner a higher bonus (Jensen 2001). However, behavioral studies in managerial accounting suggest that individuals may forgo the self-serving benefits from opportunistic reporting for two reasons, specifically, other-regarding preferences and honesty concerns (e.g., Luft 1997; Gneezy 2005; Rankin et al. 2008; Sheremeta and Shields 2013; Maas and Van Rinsum 2013).

Other-regarding preferences are preferences that consider one's own as well as others' outcomes, and they can be driven by various motives, such as altruism, fairness concerns, and aversion to inequality (Cox 2004; Fehr and Schmidt 2006; Dana et al. 2007). Since reporting decisions usually affect not only the reporter's outcome, but also those of other parties, these preferences can influence reporting behavior (Cox 2004; Dierynck 2012; Maas and Van Rinsum 2013). ${ }^{3}$ To the extent that individuals not only care about their own benefits from reporting opportunistically but are also sensitive to the potential harm to others, they will not behave in an entirely opportunistic manner (e.g., Gneezy 2005; Rankin et al. 2008; Sheremeta and Shields 2013). Consequently, other-regarding preferences can decrease opportunistic reporting.

Honesty preferences are preferences for making truthful statements (Mittendorf 2006). These preferences can also be driven by several motives, such as social conditioning, moral reasoning, and the desire to preserve favorable self-regard (Mazar et al. 2008; Rankin et al. 2008). Many people experience a disutility as a consequence of explicitly misrepresenting facts (e.g., Evans et al. 2001). In that way, an aversion to lying makes individuals less inclined to report opportunistically (Sen 1997). ${ }^{4}$

\footnotetext{
${ }^{3}$ In fact, when managers focus on their self-serving benefits and report opportunistically, they often harm other parties. This assumption seems to be relevant for many economic events (Gneezy 2005). For example, if managers inflate results when reporting to upper management in order to obtain a higher bonus, the profit of owners and shareholders ultimately decreases.

${ }^{4}$ Although some researchers have questioned the role of honesty in mitigating opportunistic reporting (e.g., Salterio and Webb 2006), others such as Rankin et al. (2008), Sheremata and Shields (2013), and Douthit and Stevens (2015) have distinguished honesty concerns from other-regarding preferences. In doing so, they show that honesty has an incremental, diminishing effect on opportunistic reporting, on top of other-regarding preferences.
} 
In sum, previous research indicates that both other-regarding preferences and honesty preferences can play a role in mitigating opportunistic reporting (e.g., Rankin et al. 2008; Douthit and Stevens 2015; Sheremeta and Shields 2013). As Fehr and Schmidt (2006) indicate, the question is not so much whether many people have other-regarding and honesty preferences, which is already supported by ample evidence, but under which conditions these preferences have important economic and social effects. One of these conditions is the organizational context since organizations can promote the saliency of honesty, for example, through contextual cues or the framing of the reporting decision (e.g., Rankin et al. 2008; Douthit and Stevens 2015; Brown et al. 2015). When honesty concerns are not salient, mainly other-regarding preferences will affect reporting behavior; whereas, when honesty concerns are made salient, both other-regarding and honesty preferences can influence reporting behavior.

In the hypotheses development below, I suggest effortful information acquisition might lead to opposing effects on other-regarding and honesty preferences. Effortful information acquisition may reduce how much other-regarding preferences matter, but it could also lead to higher honesty concerns. As such, opportunistic reporting could either increase or decrease as a consequence of effortful information acquisition. The organizational context will determine which effect will dominate by making honesty more or less salient.

\section{Development of hypotheses}

To construct my hypotheses, I rely on the theory of psychological ownership (Pierce et al. 2001, 2003). Psychological ownership is defined as a state wherein a person perceives an asset (material or immaterial in nature) as being his or hers (Pierce et al., 2001, 2003; Brown et al. 2014). The core of psychological ownership is the feeling of possessiveness and being psychologically tied to an asset; the asset becomes part of the self (Pierce et al. 2003; 
Brown et al. 2014). One of the main determinants of psychological ownership is the investment of oneself in the asset via time, effort, skills, and intellect, and some of its important psychological and behavioral effects are increased feelings of deservingness (entitlement) and responsibility (e.g., Pierce et al. 2001, 2003; Shu and Peck 2011). These effects are documented by a large body of literature for several types of assets (e.g., Van Dyne and Pierce 2004; Norton et al. 2012).

Although psychological ownership is often associated with material assets, it can also be felt toward immaterial assets, such as ideas, information, and knowledge (Pierce et al. 2001). As with material assets, individuals invest time, effort, and (intellectual) skills in the information they acquire. As such, the self-acquired information becomes intimately entwined with their egos (Davenport and Prusak 1998), and individuals might feel more entitled and personally responsible for and committed to it (Nonaka 1994). Below, I argue that these feelings in turn affect individuals' other-regarding and honesty preferences in determining opportunistic reporting.

\section{Information acquisition and other-regarding preferences}

When individuals have to make decisions, they try to maintain a sense of accountability (Hsee 1996; Schweitzer and Hsee 2002; Church et al. 2012). As such, they are more likely to make decisions in their best interest if they can make seemingly reasonable justifications for them (Kunda 1990). Previous research indicates that individuals' feelings of deservingness and entitlement can be important in justifying selfish decision making (e.g., Cameron et al. 2010, Nichol 2018). For example, Cherry (2001), Cherry et al. (2002), and Oxoby and Spraggon (2008) find in a dictator game that individuals who earn money that is to be divided between themselves and a receiver perceive themselves as more deserving of it than those who are endowed with the money. As a consequence, individuals who earn the money take their other-regarding preferences less into account and make more selfish 
decisions (i.e., they keep more money for themselves and offer less to the receiver).

Similarly, two recent working papers conclude from experiments that feelings of deservingness lead to more opportunistic reporting because they enable justification of this behavior (Douthit and Majerczyk 2015; Brown et al. 2016).

In a similar vein, individuals that exert effort to earn information can more easily justify opportunistic reporting. When individuals earn information, they invest their time, effort, skills, and intellect (De Dreu et al. 2008; Pierce et al. 2001; Zárraga and Bonache 2005). These investments engender feelings of ownership, and the individuals can justify to themselves that they deserve (are entitled to) a higher payoff (Adams 1965; Hoffman and Spitzer 1986). In the context of managerial reporting, they can allocate self-serving benefits to themselves by reporting more opportunistically, yet they will feel as though they are being fair (Dana et al. 2007). This rationalization for opportunistic reporting would not be possible with effortless information acquisition.

In sum, managers might feel that they can more easily justify a greater payoff for themselves relative to others with effortful relative to effortless information acquisition. When the reporting context does not make honesty concerns salient, these other-regarding preferences will dominate the reporting decision. As such, opportunistic reporting will be higher with effortful relative to effortless information acquisition. Hence, I predict the following effect:

HYPOTHESIS 1 . When the reporting context does not make honesty salient, opportunistic reporting will be higher with effortful relative to effortless information acquisition.

\section{Honesty preferences}

However, as already explained, individuals often also have preferences for honesty because they experience a disutility from lying (e.g., Evans et al. 2001). Indeed, most 
individuals value honesty and prefer to view themselves as being honest. Dishonest behavior requires a negative revision of these individuals' self-perception. Thus, even when honesty requires investments of effort or entails a loss of financial payoffs, individuals will adhere to it to retain their positive view of themselves (Mazar et al. 2008).

When the reporting context makes honesty concerns salient, honesty preferences become more prominent. As shown by earlier research, this prominence will cause a decrease in opportunistic reporting (Rankin et al. 2008; Douthit and Stevens 2015). To replicate this finding, I formulate my second hypothesis as follows:

HYPOTHESIS 2. When the reporting context makes honesty salient, opportunistic reporting will decrease relative to when it does not make honesty salient.

\section{Information acquisition and honesty preferences}

As argued before, expending effort to acquire information will also increase feelings of responsibility and commitment (e.g., Pierce et al. 2001, 2003). Lying about the effortfully earned information could therefore also have an impact on individuals' view of themselves to a larger (more negative) extent (Mazar et al. 2008; Schwartz 1968). Indeed, the feelings of ownership, responsibility, and commitment could make people more mindful of their moral standards, and any dishonest action is more likely to be reflected in their self-concept. In the same vein, feelings of ownership and responsibility play an important role in moral disengagement theory. This theory describes the cognitive reframing of (un)ethical behavior

such that ethical standards (do not) apply to oneself in a particular context (Bandura 1999). According to this theory, individuals with increased feelings of responsibility are more likely to make ethical decisions (e.g., Bandura 1999; Detert et al. 2008).

Recent experimental findings are in line with this theory. In a cost reporting setting, Libby et al. (2018) find that managers with more responsibility report more honestly than those with less responsibility. In a more abstract setting, Charness et al. (2019) find that 
participants physically handling money cheat remarkably less compared to when the experimenter handles the money. The authors argue that individuals may be more honest when they feel more responsible. They also posit that an increased moral cost of lying might make it more difficult to cheat and maintain a positive self-image. Although Charness et al. (2019) mainly speculate and do not theorize or empirically show much about the mechanism behind their finding, it is consistent with the theory outlined above: investing time, effort, and skills in an asset increases feelings of responsibility and ultimately decreases unethical behavior.

In line with the above, I argue that it becomes easier to displace responsibility when information is acquired without effort; whereas, increased feelings of ownership, commitment, and responsibility will arise when information is acquired in an effortful way. From the preceding arguments, it follows that managers might care more about honesty when information is acquired in an effortful way relative to an effortless way and expending effort to acquire information can thus discourage unethical actions. As such, a decrease in opportunistic reporting caused by a context that makes honesty concerns salient will be larger for information that is earned in a more effortful way since individuals care more about honesty in this case. Therefore, I predict the following interaction effect:

HYPOTHESIS 3. The decrease in opportunistic reporting associated with a reporting context that makes honesty salient will be larger for effortful relative to effortless information acquisition.

\section{Method}

\section{Participants and design}

I examine the effect of information acquisition on managerial reporting via a budget reporting experiment. To test my hypotheses, I conducted a computer-based $2 \times 2$ experiment 
with z-Tree as the software package (Fischbacher 2007). ${ }^{5}$ In total, 164 undergraduate business students from a large European university participated in the experiment (36 percent female, mean age about 22 years). ${ }^{6}$ The experiment was conducted in eight sessions, with 20 or 22 participants per session. A session consisted of eight decision rounds and lasted about 55 minutes on average. Participants received a course credit and earned on average $€ 8.89$ for their participation. Their total payoff was calculated as the sum of their payoffs in each decision round of the experiment.

The research design for this study is broadly based on the typical setting used in budget reporting experiments (e.g., Douthit and Stevens 2015; Evans et al. 2001; Hannan et al. 2006; Rankin et al. 2008). Participants were randomly assigned to the role of manager or owner, and they remained in the same role throughout the experiment. Every manager was randomly paired with an owner and was rematched with a different owner after every decision round. None of the participants ever learned the identity of the person with whom they were paired.

\section{Task}

In each of the eight decision rounds, managers had to implement a project that incurred costs. The costs of implementing the eight projects were randomly determined upfront and were the same for every session. Both manager and owner knew that the implementation cost of the project would fall within a range of 0 to 200 , with a uniform distribution of $[0,1,2,3,4,5, \ldots, 199,200]$. The numbers represented euro cents; hence a cost of 100 equaled $€ 1.00$. Managers and owners also knew that every project yielded revenue of 200 ( $€ 2.00)$, but only managers could find out the actual implementation costs. To

\footnotetext{
${ }^{5}$ Approval was granted by the institution where the experiment took place.

${ }^{6}$ One participant was removed from the analyses after indicating the instructions were not understood.
} 
inform the owner about this project, managers had to submit a budget report. These specifics were explained to all participants in the experimental instructions.

In this setting, I manipulated the acquisition of information (endowed information versus earned information) and the reporting context (no honesty trigger versus honesty trigger) between participants.

\section{Manipulations}

Information acquisition: endowed versus earned information

In the endowed information condition, managers received a private cost form in every decision round. This cost form revealed the project's actual implementation cost. ${ }^{7}$ In the earned information condition, managers had to expend effort to learn the actual cost. In particular, they had to solve a number series puzzle in every decision round (based on Haesebrouck et al. [2015]) to find out the project's implementation cost. The solution to the puzzle was the actual cost for that period. Number series puzzles provide a sequence of numbers that follow a discernable pattern. Managers had to recognize the pattern to obtain the next number in the sequence. An example of a number series puzzle used in one of the decision rounds is the following: $69,75,76,80,83,85,90,90$, In this example, the odd and even number positions follow different patterns. For the numbers in the odd positions $(69,76,83$, etc.), the pattern is based on adding 7 to the previous number to find the next number. For the numbers in the even positions $(75,80,85$, etc.), the pattern is based on adding 5 to the previous number to find the next number. The number we are looking for in the overall sequence is in the odd position; therefore, the solution is $97(90+7)$. Accordingly, the actual implementation cost of the project is 97 in this decision round.

\footnotetext{
${ }^{7}$ Note that in a typical budgeting experiment, managers are informed about their private information in this way (e.g., Rankin et al. 2008; Douthit and Stevens 2015).
} 
Because these number series puzzles could be difficult to solve, managers who had trouble solving a puzzle could request hints after working on it for several minutes. In that way, all managers could find out the project's actual implementation cost. ${ }^{8}$ First, a button labeled "HINT 1" appeared on the computer screen, followed several minutes later by a button labeled "HINT 2." If managers pressed these buttons, information that would help them solve the puzzle was provided. Even when the hints became available, the instructions urged managers to try their best to solve the number series puzzle without them. However, they could press the HINT 1 button if they became stuck. Further, the instructions asked them to only press the HINT 2 button if the first hint still did not allow them to solve the puzzle. In total, 16 hints could be requested (two hints per number series puzzle, one number series puzzle for each of the eight rounds). Summed up over the eight rounds, the average participant requested 1.88 out of 16 hints (with a standard deviation of 1.25). With the help of the hints, participants were always able to solve the puzzles.

In summary, at the start of each decision round, both the manager and the owner knew that the actual implementation cost would fall within a range of 0 to 200 . Next, managers found out the actual implementation cost, either from reading their private cost form (endowed information condition) or by solving a number series puzzle (earned information condition). Managers always learned this cost, while owners would never learn it. All participants were aware of this information asymmetry.

Reporting context: no honesty trigger versus honesty trigger

Next, I use the "mode of reporting" manipulation as employed by Rankin et al. (2008) to trigger honesty concerns. Specifically, I manipulate the reporting context by varying whether the report is framed as a mere allocation of profit or as an ethical dilemma. Thereby,

\footnotetext{
${ }^{8}$ Not solving a puzzle was not an option. Participants could not continue in a decision round if they did not solve the puzzle of that round.
} 
managers either had to (1) report (allocate) a portion of the project's profit to the owner (no honesty trigger condition), or (2) report the project's cost to the owner (honesty trigger condition). As explained below, the allocated profit or reported cost determined the payoffs of managers and owners in such a way that more budgetary slack (i.e., allocating less profit or reporting a higher cost) would lead to a higher (lower) payoff for managers (owners). Managers also received a fixed salary of $100 .^{9}$

In the no honesty trigger condition, managers reported a portion of the project's profit to be returned to the owner. Managers could allocate any portion of the project's profit between 0 and the total profit (200 minus the project's actual cost) to the owner. The allocated amount was the owner's payoff. The payoff to the manager was the remainder of the profit (total profit minus the portion allocated to the owner) plus the fixed payment of 100.

In the honesty trigger condition, managers reported the project's cost to the owner and could keep any difference between the actual and reported cost. Hence, the payoff to the managers was, in addition to the 100 fixed salary, the reported cost minus the actual cost to implement the project. The payoff to the owner was 200 (i.e., the revenue of the project) minus the reported cost. Table 1 summarizes these payoffs of managers and owners across the reporting context conditions.

\section{[Insert Table 1 here]}

In both the honesty and the no honesty trigger condition, more opportunistic reporting (i.e., reporting a smaller profit allocation or a higher cost) increases the manager's payoff but decreases the owner's payoff. As such, to the extent that managers care about the owners'

\footnotetext{
${ }^{9}$ Previous research also provides managers with a fixed salary to make sure no extreme tension exists between their payoff and their preferences to report honestly (e.g., Rankin et al. 2008). Without a fixed salary, managers who report honestly would always have a payoff of zero.
} 
payoff, their other-regarding preferences should decrease opportunistic reporting in both conditions. However, the motivation to report honestly should be more salient in the honesty trigger condition because making an untrue representation of facts is only possible in this condition. In particular, since managers in the no honesty trigger condition are only asked to divide the profit and report the portion they allocate to the owner, they cannot lie, even if they induce slack. Indeed, this condition forces managers to frame the budgeting task as merely an allocation of the profit. In the honesty trigger condition, however, preferences for honesty, on top of other-regarding preferences, can influence managers' reporting decision because managers who report an untrue cost are explicitly lying to the owner. Hence, I capture the effect of other-regarding preference by studying the amount of slack in the no honesty trigger condition and the incremental effect of honesty by studying the difference in slack between the condition with and without the honesty trigger. ${ }^{10}$ This approach enables me to distinguish the effect of other-regarding preferences from honesty preferences in mitigating opportunistic reporting. In that way, I can test the theory explained above that suggests opposing effects of endowed information relative to earned information for these two preferences.

\section{Procedure}

I randomly assigned participants to a computer terminal situated in one of two rooms. Participants in one room were managers, and participants in the other room were owners. Participants started by reading their instructions, after which they completed a short quiz to ensure they understood their role, the task, and the payoff structure. Participants could only move on to the next question once they answered the current question correctly. In addition, there was a "practice tool" before managers had to make their real decision to make sure they knew the consequences of their decisions. With this tool, they could calculate the impact of

\footnotetext{
${ }^{10}$ Hence, to compare the effect of honesty for the earned and endowed information condition, I should study the interaction effect (i.e., test whether the decrease when moving from no honesty to the honesty trigger condition is equal for endowed versus earned information).
} 
the allocated profit/reported cost of their choice on their own and the owners' payoff. After the eight decision rounds, participants were asked to complete the post-experimental questionnaire, which included questions on the factors influencing managers' decisions and on participants' demographics and personality traits.

\section{Results}

\section{Descriptive statistics}

Before looking into my main variables of interest, I test for random assignment across conditions with respect to demographics and personality traits like age, work experience, and social value orientation. Results show no significant differences, except for Machiavellianism, which is somewhat lower in the No Honesty Trigger/Earned Information condition and the Honesty Trigger/Endowed Information condition compared to the other two conditions (see panel A of Table 2). ${ }^{11}$ Since previous research shows that individuals who are more Machiavellian are inclined to induce more slack in a budgeting setting (e.g., Hartmann and Maas 2010), extracting the variation from this covariate enhances my ability to statistically isolate reporting effects apart from any personality traits. Hence, I adjust for Machiavellianism and include it as a covariate in all my analyses reported below.

Panel A of Table 2 reports the descriptive statistics of the main dependent variable, Average Slack. This measure is calculated as the eight-period mean of slack claimed over slack available. ${ }^{12}$ A higher value for average slack indicates that the manager reported more

\footnotetext{
${ }^{11}$ The following four items, measured on a 7-point Likert Scale with scores ranging from 1 ("I totally disagree”) to 7 ("I totally agree"), capture Machiavellianism: "I tend to manipulate others to get my way," "I have used deceit or lied to get my way," "I have used flattery to get my way," and "I tend to exploit others towards my own end" (Jonason and Webster 2010). A higher score indicates the individual has a more Machiavellian personality. Machiavellianism is known to be a stable personality trait (Jonason and Webster 2010). Individuals with this trait tend to detach from considerations of ethics and perform actions that profit the self (Schepers 2003).

${ }^{12}$ Note that the maximum slack available is equal across conditions since the cost in a specific period was the same for every participant. More particularly, the cost sequence for the eight periods was 159, 97, 62, 17, 4, 145, 104, and 34. Hence, if a manager reported, for example, a cost of 179 in the first period, he or she claimed 20 of the available slack of $41(=200-159)$. Consequently, the slack claimed over slack available to this manager equals $49 \%(=20 / 41)$ in the first period.
} 
opportunistically. From the descriptive statistics, it is apparent that average slack is higher for earned information than for endowed information when no honesty trigger is present. However, in moving from the no honesty to the honesty trigger condition, average slack decreases. This decrease seems to be larger for earned information than for endowed information, indicating that the effect of honesty is more pronounced for earned information. Figure 1 presents this evidence graphically, and it is consistent with my three hypotheses. In the following section, I formally test these hypotheses.

[Insert Table 2 here]

[Insert Figure 1 here]

\section{Hypotheses test}

I performed an analysis of covariance (ANCOVA) test with Average Slack as the dependent variable, Information Acquisition and Reporting Context as independent variables, and Machiavellianism as a covariate to test hypothesis 1, 2, and 3 (tabulated in panel A of Table 3). ${ }^{13,14}$ Given the specific pattern predicted in my hypotheses, I also performed contrast coding (tabulated in panel B of Table 3).

Recall that Hypothesis 1 posits that when the reporting environment does not make honesty salient, opportunistic reporting will be higher with effortful relative to effortless information acquisition. In the experiment, Hypothesis 1 is supported if managers in the no honesty trigger condition induce more slack when information is earned relative to being endowed. Descriptive statistics reported earlier confirmed slack is higher for earned information than for endowed information when no honesty trigger is present (see panel A of Table 2). To formally test whether this difference is significant, I examine the simple effect

\footnotetext{
${ }^{13}$ I also ran a repeated-measure ANCOVA to test for period effects. However, there is no significant effect from period.

${ }^{14}$ To test whether Machiavellianism is interacting with one of my main variables of interest, I run a regression analysis with Average Slack as dependent variable and the main effects, two- and three-way interaction effects of Machiavellianism, Knowledge Acquisition, and Mode of Reporting as independent variables. In this regression, the two- and three-way interaction effects with Machiavellianism are not significant (not tabulated).
} 
of information acquisition within the no honesty trigger condition. Consistent with H1, the simple effect test shows that average slack is significantly higher for earned than for endowed information when the context does not trigger honesty $(F=3.56, p=0.03) .{ }^{15}$ Hence, managers' own payoff gets a higher weight relative to the owners' payoff when information is earned relative to endowed, leading to more budgetary slack (opportunistic reporting) with earned information.

[Insert Table 3 here]

Hypothesis 2 posits that opportunistic reporting will decrease when moving from the unsalient to the salient honesty condition. To test this hypothesis, I study the main effect of the reporting context. As indicated by the ANCOVA $(F=9.18, \mathrm{p}<0.01)$, the reporting context has a highly significant effect on budgetary slack. Descriptive statistics in panel A of Table 2 and the graphical depiction in Figure 1 also show that the effect follows the expected direction. I therefore conclude that the evidence supports $\mathrm{H} 2$.

Hypothesis 3 predicts that the decrease in opportunistic reporting associated with a reporting context that makes honesty salient, should be larger with earned than with endowed information. The ANCOVA test reported in panel A of Table 3 shows that there is a significant interaction effect of information acquisition and reporting context on average slack $(F=4.13, p=0.02)$, which provides support for this hypothesis. However, since H3 predicts a specific pattern, I also rely on contrast coding (Buckless and Ravenscroft 1990; Guggenmos et al. 2018). Consistent with the patterns predicted across my hypotheses, I define the contrasts as 2 for the earned information/no honesty trigger condition, 1 for the endowed information/no honesty trigger condition, -1 for the endowed information/honesty trigger condition, and -2 for the earned information/honesty trigger condition. To test the

\footnotetext{
${ }^{15}$ Unless stated otherwise, p-values are reported on a one-tailed basis, given the directional predictions for the effects.
} 
significance of these contrasts, I use the three-part approach suggested by Guggenmos et al. (2018). First, after a visual evaluation of Figure 2, I conclude that the observed data fit the predicted pattern reasonably well. Second, panel B of Table 3 reports the p-value of the contrast, which provides support for Hypothesis $3(\mathrm{~F}=12.74, \mathrm{p}<0.01)$. In addition, the $\mathrm{p}$ value of the residual variance is insignificant $(\mathrm{F}=0.73, \mathrm{p}=0.48)$, indicating that the model contrast explains all the between-group variance. Third, the size of the contrast variance residual indicates that about $10 \%$ of the between-cells variance remains after accounting for the contrast $\left(q^{2}=0.08\right.$, out of a total between-cells variance of 0.77$)$. As such, the observed pattern is a match to the hypothesized shape. In sum, since the decrease in slack when moving from no honesty to the honesty trigger condition is larger for earned than for endowed information, I find support for my hypothesis that honesty concerns have a larger effect in mitigating slack for earned information than for endowed information.

\section{Supplemental analyses}

\section{Motivation}

In the post-experimental questionnaire, I included several questions to gain a better understanding of managers' motivation in making their reporting choices. I focus on managers' other-regarding preferences and their motivation to be honest. All questions are presented on a Likert scale with $1=$ strongly disagree and $7=$ strongly agree .

First, I investigate managers' fairness motivation when making their reporting choice, an important aspect of other-regarding preferences, by examining the statement "I wanted to treat the owner fairly." In my theory development and the analyses above, I assume that this type of motivation does not differ between conditions. Indeed, in order to attribute the difference between the no honesty and honesty trigger condition to the incremental effect of honesty, other motivations should remain constant. Results are in line with this assumption and show that the fairness measure does not differ significantly across the four conditions 
(descriptive statistics tabulated in Table 2 panel A, two-tailed p-values of the main and interaction effects all larger than 0.43). Within the no honesty trigger condition, the mean is 4.10 for endowed information and 3.71 for earned information (two-tailed $\mathrm{p}=0.43$ ). Recall that managers induced more slack with earned relative to endowed information when the reporting context did not trigger honesty. Hence, this fairness measure being rather similar across conditions also indicates that managers who earn information do not feel that they treat the owner less fairly by claiming more slack. In other words, when a trade-off is made between their own wealth maximization and others' payoffs, managers might feel justified in maximizing their wealth to a higher extent with earned information. The relatively high average (5.48) of the statement "Since I expended effort to find out the actual cost, I feel like I deserve a higher payoff" for participants in the earned information condition without honesty trigger provides some additional support for this claim. The average on this question for participants who earned information in the condition with the honesty trigger equals 4.36, which is significantly lower $(\mathrm{p}=0.01)$, consistent with what theory suggests.

Second, when I asked participants whether it is unethical to report a cost (honesty trigger condition) or to allocate a portion of the profit (no honesty trigger condition) that results in a significantly higher payoff for managers than for owners, managers with earned versus endowed information evaluated this question differently (see Table 2 panel A for descriptives). A main effect exists for the reporting context $(p=0.01)$, in that managers in the honesty trigger condition agree with this statement more than managers in the no honesty trigger condition. Since the reporting context manipulation is supposed to increase the salience of honesty, this result is in line with my expectations. However, closer examination of the honesty trigger condition reveals that the average is marginally significantly higher for earned information than for endowed information (4.86 for earned information versus 4.04 
for endowed information, $p=0.06$ ). Thus, I find some evidence that ethical concerns are triggered more with earned information, which is consistent with theory.

\section{Earned information: perceived task difficulty and stress}

Finally, I study two aspects related to earning information in more detail: perceived task difficulty and stress. Task difficulty refers to the amount of attention and mental effort required for successful performance (Kahneman 1973; Ashton 1990). I expect that the more difficult the task was perceived to be, the more managers should feel they expended effort to acquire their information. Similarly, stress is an important indicator of effort (Shields et al. 2000; Bonner and Sprinkle 2002). Consequently, the more stressful it was for managers to solve the puzzles, the more they should feel they expended effort to acquire their information. Given the theory, these feelings should in turn be reflected in the amount of opportunistic reporting. That is, feeling that information was acquired in an effortful way should lead to more opportunistic reporting in the no honesty trigger condition, but it should decrease opportunistic reporting to a larger extent when moving to the honesty trigger condition.

To test this interpretation, I run some additional analyses on the earned information sample. In the post-experimental questionnaire, I included the following statement to measure the perceived task-difficulty "Solving these number series puzzles was difficult." Managers responded using a 7 -point Likert scale with $1=$ strongly disagree and $7=$ strongly agree. Scores range from 2 to 7 with a mean of 3.24. I split managers into low- and high-difficulty subsamples and graphically present the corresponding Average Slack measures across the reporting contexts in panel A of Figure 2. ${ }^{16}$ This representation shows that slack is higher

\footnotetext{
${ }^{16}$ I expect that using a higher number of hints when solving the puzzle reduces the feeling that information was earned, while a higher perceived task difficulty increases the feeling that information was earned. The number of hints used is rather low (on average 1.88 out of 16 hints were requested), but nevertheless, the variable Task Difficulty is significantly correlated with the number of hints used $(\mathrm{r}=0.53$, two-tailed $\mathrm{p}<0.01)$. Hence, the number of hints used and the perceived task difficulty are positively correlated but will influence slack in opposing directions. When I control for the number of used hints in the reported tests, all effects remain significant at the same level.
} 
with greater perceived task difficulty when the reporting context does not trigger honesty ( 0.73 for low difficulty versus 0.79 for high difficulty). In contrast, slack is lower when the task is perceived as more difficult relative to less difficult with an honesty trigger $(0.56$ for low difficulty versus 0.39 for high difficulty). In line with my main analyses, I test the significance of these results with an ANCOVA and a planned contrast with codes of 2, 1, -1, and -2 for the high perceived task difficulty/no honesty trigger condition, low perceived task difficulty/no honesty trigger condition, low perceived task difficulty/honesty trigger condition, and high perceived task difficulty/honesty trigger conditions, respectively. The simple effects test indicates the effect of task difficulty within the no honesty trigger condition is not significant $(\mathrm{p}=0.26)$, but the reporting context significantly affects Average Slack $(\mathrm{p}<0.01)$. The interaction effect of the ANCOVA $(\mathrm{p}=0.05)$ and the planned contrast are also significant $(\mathrm{F}=17.37, \mathrm{p}<0.01$, tabulated in Table 4 panel $\mathrm{A})$, indicating that higher perceived task difficulty decreases slack to a larger extent when moving from the no honesty to the honesty trigger condition. ${ }^{17}$

\section{[Insert Figure 2 here] \\ [Insert Table 4 here]}

Similar results are obtained for the level of stress participants felt when solving the puzzles. The more stress managers felt, the more likely they should feel that they expended effort to acquire their information. Managers indicated on a 7-point Likert response scale with $1=$ strongly disagree and $7=$ strongly agree how much they agreed with the following statement: "I felt stressed while solving these number sequence puzzles." Scores range from 1 to 6 with a mean of 2.90. I split managers into low- and high-stressed subsamples and graphically present their Average Slack means across the reporting context conditions in

\footnotetext{
${ }^{17}$ The insignificance and the small size of the contrast residual variance as reported in Panel A of Table 4 strengthen this inference.
} 
Figure 2, panel B. ${ }^{18}$ In the no honesty trigger condition, managers induced marginally significantly more slack when they experienced higher stress $(0.68$ for low stress versus 0.83 for high stress, $\mathrm{p}=0.07)$. The main effect in the ANCOVA test shows the reporting context has a significant effect on Average Slack $(\mathrm{p}<0.01)$. Moreover, the interaction effect between stress and honesty trigger is marginally significant $(\mathrm{p}=0.08)$. The planned contrast with codes $2,1,-1$, and -2 for high perceived stress/no honesty trigger, low perceived stress/no honesty trigger, low perceived stress/honesty trigger, and high perceived stress/honesty trigger conditions, respectively, also show the predicted pattern is highly significant $(\mathrm{F}=$ 16.91, $\mathrm{p}<0.01$, see panel B of Table 4). ${ }^{19}$

In summary, these results indicate that feeling that information is acquired in an effortful way influences the creation of slack in a consistent manner. When managers felt more strongly that they expended effort to acquire information (measured by higher perceived task difficulty and more stress), they reported more opportunistically when the reporting context did not trigger honesty. However, with higher perceived task difficulty and more stress, the decrease in opportunistic reporting was larger when moving to the condition that triggers honesty, which indicates honesty considerations are stronger for managers who feel that their information was acquired in an effortful way.

\section{Discussion}

This paper investigates whether managers' tendency to report opportunistically is affected by how they acquired the information they need to report. The theory I develop suggests there might be opposing effects from information acquisition on the two variables

\footnotetext{
18 The stress variable used in this analysis is marginally significantly correlated with the number of hints used ( $\mathrm{r}$ $=-0.26$, two-tailed $\mathrm{p}=0.10$ ). When I include the number of hints used as a covariate, all $\mathrm{p}$-values remain at the same significance level.

${ }^{19}$ The insignificance and the small size of the contrast residual variance as reported in panel B of Table 4 strengthen this inference.
} 
previously identified as mitigating opportunistic reporting: other-regarding and honesty preferences. By manipulating the reporting context in an experiment, I can examine the conditions under which each effect will dominate. I also manipulate whether participants are endowed with their information or have to exert intellectual effort to earn it. Results indicate that earning information increases opportunistic reporting because individuals feel that they deserve the benefits of it. However, when the reporting context triggers honesty concerns, the negative effect of earned information on opportunistic reporting is alleviated because managers care more about honesty with earned information than with endowed information.

These findings contribute to a better understanding of information acquisition, a crucial aspect of various accounting settings, including auditing, budgeting, financial statements, and taxes (e.g., Balakrishnan 1991; Einhorn and Ziv 2007; Sansing 1993; Nelson and Tayler 2007). Although effortful information acquisition has received some attention in the financial statements literature (Nelson and Tayler 2007), studying this factor in other domains can provide valuable additional insights. Indeed, whereas Nelson and Tayler (2007) investigate how effortful information acquisition affects perceived importance and weighting of this information for financial statement users, I focus on how it influences other-regarding and honesty concerns and the subsequent managerial reporting decisions. In that way, my findings also have important implications for practice. For example, in complex business environments in which information acquisition is labor intensive, making honesty concerns more salient (e.g., by incorporating honesty into the reporting context) may be more advisable relative to environments in which information is acquired more easily.

I also make a contribution to the budgeting literature by taking a crucial real-life aspect into account. In previous experiments, participants were usually endowed with the information they had to report, but I recognize that acquiring information requires effort. Consequently, I can show that effortful information acquisition has opposing effects on the 
impact of other-regarding preferences and honesty preferences in mitigating opportunistic reporting.

This study has several limitations, which provide opportunities for future research. For example, since owners never learn the project's actual implementation cost, managers cannot show that they acquire and report correct information. Hence, impression management cannot play a role, which might be especially important for earned information. Future research can examine how impression management affects opportunistic reporting with earned information. In addition, I did not allow discretion in the earned information condition (i.e., managers did not have the choice to earn information or to be endowed with it). Although discretion in effortless information acquisition has already been investigated in earlier research (e.g., Church et al. 2014), examining whether discretion in costly information acquisition affects managerial reporting could be interesting. Moreover, I deliberately focused on cognitive effort in my experiment since this type of effort is often necessary to acquire information in today's business environment. However, future research might investigate whether different types of effort to acquire information (cognitive, mechanical, etc.) affect decisions and judgments in a similar way. Finally, the information participants acquired in my experiment did not involve any uncertainty. Hence, factors such as riskaverseness and judgment could not play a role. Future research can examine how adding such contextual variables could potentially affect my findings. 


\section{References}

Adams, J. S. 1965. Inequity in social exchange. In Advances in social psychology. Vol. 2, edited by L. Berkowitz, 267-99. New York: Academic Press.

Ashton, R. H. 1990. Pressure and performance in accounting decision settings: Paradoxical effects of incentives, feedback, and justification. Journal of Accounting Research 28: $148-80$.

Balakrishnan, R. 1991. Information acquisition and resource allocation decisions. The Accounting Review 66 (1): 120-139.

Bandura, A. 1999. Moral disengagement in the perpetration of inhumanities. Personality and Social Psychology Review 3: 193-209.

Bens, D. A., T. H. Goodman, and M. Neamtiu. 2012. Does investment-related pressure lead to misreporting? An analysis of reporting following M\&A transactions. The Accounting Review 87 (3): 839-65.

Berger, L., K. Fiolleau, and C. MacTavish. 2018. I know something you don't know: How relative performance and pay for performance affect employee decisions to share information with other employees. Journal of Management Accounting Research (in press).

Bol, J. C., and J. Leiby. 2015. Status motives and agent-to-agent information sharing: How evolutionary psychology shapes agents' responses to control system design. Working paper, http://ssrn.com/abstract=2645804.

Bonner, S. E., and G. B. Sprinkle. 2002. The effects of monetary incentives on effort and task performance: theories, evidence, and a framework for research. Accounting, Organizations and Society 27 (4): 303-45.

Brown, G., J. L. Pierce, and C. Crossley. 2014. Toward an understanding of the development of ownership feelings. Journal of Organizational Behavior 35(3): 318-38.

Brown, J., L. E. Chan, J. Choi, H. Evans, and D. Moser. 2016. Can working harder lead managers to misreport more often? How managerial effort influences reporting. Working paper.

Brown, J. L., J. H. Evans III, and D. V. Moser. 2009. Agency theory and participative budgeting experiments. Journal of Management Accounting Research 21: 317-45.

Brown, J. L., J. G. Fisher, S. A. Peffer, and G. B. Sprinkle. 2017. The effect of budget framing and budget-setting process on managerial reporting. Journal of Management Accounting Research 29 (1): 31-44.

Bruns, W. J., and S. M. McKinnon. 1993. Information and managers: A field study. Journal of Management Accounting Research 5: 84-108.

Buckless, F. A., and S. P. Ravenscroft. 1990. Contrast coding: A refinement of ANOVA in behavioral analysis. The Accounting Review 65 (4): 933-45.

Cameron, J. S., D. Miller, and B. Monin. 2010. Deservingness and unethical behavior in loss and gain frames. Unpublished manuscript.

Caskey, J., V. Nagar, and P. Petacchi. 2010. Reporting bias with an audit committee. The Accounting Review 85 (2): 447-81.

Charness, G. 2000. Responsibility and effort in an experimental labor market. Journal of Economic Behavior and Organization 42: 375-84.

Charness, G., C. Blanco-Jimenez, L. Ezquerra, and I. Rodriguez-Lara. 2019. Cheating, incentives and money manipulation. Experimental Economics 22: 155-77.

Cherry, T. L. 2001. Mental accounting and other-regarding behavior: Evidence from the lab. Journal of Economic Psychology 22: 605-15.

Cherry, T. L., P., Frykblom, and J. F. Shogren. 2002. Hardnose the dictator. American Economic Review 92(4): 1218-21. 
Church, B. K., R. L. Hannan, and X. Kuang. 2012. Shared interest and honesty in budget reporting. Accounting Organization and Society 37: 155-67.

Church, B. K., R. L. Hannan, and X. Kuang. 2014. Information acquisition and opportunistic behavior in managerial reporting. Contemporary Accounting Research 31 (2): 398-419.

Coricelli, G., M. Joffily, C. Montmarquette, and M. Villeval. 2010. Cheating, emotions, and rationality: An experiment on tax evasion. Experimental Economics 13 (2), 226-47.

Cox, J. C. 2004. How to identify trust and reciprocity. Games and Economic Behavior 46: 26081.

Dana, J., R. A. Weber, and J. X. Kuang. 2007. Exploiting moral wiggle room: Experiments demonstrating an illusory preference for fairness. Economic Theory 33: 67-80.

Davenport, T. H., and L. Prusak. 1998. Working knowledge: How organizations manage what they know. Boston: Harvard Business School Press.

Davidson, B. I., and D. E. Stevens. 2013. Can a code of ethics improve manager behavior and investor confidence? An experimental study. The Accounting Review 88 (1): 51-74.

de Bruin, B. 2013. Epistemic integrity in accounting: Accountants as justifiers in joint epistemic agents. Business \& Professional Ethics Journal 32 (1-2): 109-30.

De Dreu, C. K. W., B. A. Nijstad, and D. van Knippenberg. 2008. Motivated information processing in group judgment and decision making. Personality and Social Psychology Review 12 (1): 22-49.

Detert, J. R., L. K. Treviño, and V. L. Sweitzer. 2008. Moral disengagement in ethical decision making: A study of antecedents and outcomes. Journal of Applied Psychology 93 (2): 374-91.

Dierynck, B. 2012. Do you fear your (heterogeneous) peers? An experimental investigation about peer-induced fairness concerns in a capital budgeting setting. Working paper, http://dx.doi.org/10.2139/ssrn.1909808.

Ditillo, A. 2004. Dealing with uncertainty in knowledge-intensive firms: The role of management control systems as knowledge integration mechanisms. Accounting, Organizations and Society 29: 401-21.

Douthit, J., and M. Majerczyk. 2015. Experimental role assignment and the effect of the perceived legitimacy of the superior's position on budgetary reporting. Working paper.

Douthit, J. D., and D. E. Stevens. 2015. The robustness of honesty effects on budget proposals when the superior has rejection authority. The Accounting Review 90 (2): 467-93.

Einhorn, E., and A. Ziv. 2007. Unbalanced information and the interaction between information acquisition, operating activities, and voluntary disclosure. The Accounting Review 82 (5): 1171-94.

Evans, J. H., R. L. Hannan, R. Krishnan, and D. V. Moser III. 2001. Honesty in managerial reporting. The Accounting Review 76 (4): 537-59.

Ewusi-Mensah, K. 1981. The external organizational environment and its impact on management information systems. Accounting, Organizations and Society 6 (4): 30116.

Fehr, E., and K. M. Schmidt. 2006. The economics of fairness, reciprocity and altruismExperimental evidence and new theories. Handbook of the Economics of Giving, Altruism and Reciprocity 1: 615-91.

Fischbacher, U. 2007. z-Tree: Zurich toolbox for ready-made economic experiments. Experimental Economics 10 (2): 171-8.

Fischbacher, U., and U. Stefani. 2007. Strategic errors and audit quality: An experimental investigation. The Accounting Review 82 (3): 679-704.

Gneezy, U. 2005. Deception: The role of consequences. The American Economic Review 95 (1): 384-94. 
Guggenmos, R. D., M. D. Piercey, and C. P. Agoglia. 2018. Custom contrast testing: Current trends and a new approach. The Accounting Review 93 (5): 223-44.

Haesebrouck, K., A. Van den Abbeele, and M. Cools. 2018. Status differences and knowledge transfer: The effect of incentives. The Accounting Review 93 (1): 213-34.

Haesebrouck, K., A. Van den Abbeele, and M. G. Williamson. 2015. The effects of knowledge sharing on helping behavior: Implications for reward system design. Working paper, http://dx.doi.org/10.2139/ssrn.2648298.

Hannan, R. L., F. W. Rankin, and K. L. Towry. 2006. The effect of information systems on honesty in managerial reporting: A behavioral perspective. Contemporary Accounting Research 23 (4): 885-915.

Hartmann, F. G. H., and V. S. Maas. 2010. Why business unit controllers create budget slack: Involvement in management, social pressure, and machiavellianism. Behavioral Research in Accounting 22 (2): 27-49.

Hoffman, E., and M. L. Spitzer. 1985. Entitlements, rights, and fairness: An experimental examination of subjects' concepts of distributive justice. The Journal of Legal Studies 14 (2): 259-97.

Hsee, C. 1996. Elastic justification: How unjustifiable factors influence judgements. Organizational Behavior and Human Decision Processes 66 (1): 122-9.

Huber, G. P. 1991. Organizational learning: The contributing processes and the literatures. Organization Science 2 (1): 88-115.

Hurley, P. J., and B. W. Mayhew. 2019. Market reactions to a high-quality auditor and managerial preference for audit quality. Working paper, https://ssrn.com/abstract=2258865.

Hwang, Y., D. H. Erkens, and J. H. Evans III. 2009. Knowledge sharing and incentive design in production environments: Theory and evidence. The Accounting Review 84 (4): $1145-70$.

Inkpen, A. C. 2000. Learning through joint ventures: A framework of knowledge acquisition. Journal of Management Studies 37 (7): 1019-43.

Jensen, M. C. 2001. Corporate budgeting is broken, let's fix it. Harvard Business Review 79: 94-101.

Jonason, P. K., and G. D. Webster. 2010. The dirty dozen: A concise measure of the dark triad. Psychological Assessment 22 (2): 420-32.

Kahneman, D. 1973. Attention and Effort. Englewood Cliffs, NJ: Prentice-Hall.

Königsgruber, R., and S. Palan. 2015. Earnings management and participation in accounting standard-setting. Central European Journal of Operations Research 23 (1): 31-52.

Kunda, Z. 1990. The case for motivated reasoning. Psychological Bulletin 108 (3): 480-98.

Li, J. J., L. Poppo, and K. Z. Zhou. 2010. Relational mechanisms, formal contracts and local knowledge acquisition by international subsidiaries. Strategic Management Journal 31: 349-70.

Libby, T., C. A. Proell, and S. D. Smith. 2018. Difficult cost goals and conflicting honesty incentives: The influence of decision responsibility. Journal of Management Accounting Research (in press).

Luft, J. L. 1997. Fairness, ethics and the effect of management accounting on transaction costs. Journal of Management Accounting Research 9: 199-216.

Maas, V. S., and M. Van Rinsum. 2013. How control system design influences performance misreporting. Journal of Accounting Research 51 (5): 1159-86.

Mazar, N., O. Amir, and D. Ariely. 2008. The dishonesty of honest people: A theory of selfconcept maintenance. Journal of Marketing Research 45 (6): 633-44.

Milgrom, P., and J. Roberts. 1992. Economics, organization and management. Englewood Cliffs, NJ: Prentice Hall. 
Mittendorf, B. 2006. Capital budgeting when managers value both honesty and perquisites. Journal of Management Accounting Research 18 (1): 77-95.

Nelson, M. W., and W. B. Tayler. 2007. Information pursuit in financial statement analysis: Effects of choice, effort, and reconciliation. The Accounting Review 82 (3): 731-58.

Nichol, J. E. 2018. The effects of contract framing on misconduct and entitlement. The Accounting Review (in press).

Nonaka, I. 1994. A dynamic theory of organizational knowledge creation. Organization Science 5 (1): 14-37.

Norton, M. I., D. Mochon, and D. Ariely. 2012. The IKEA effect: When labor leads to love. Journal of Consumer Psychology 22(3): 453-60.

Omer, T. C., and R. J. Yetman. 2007. Tax misreporting and avoidance by nonprofit organizations. Journal of the American Taxation Association 29 (1): 61-86.

Oxoby, R., and J. Spraggon. 2008. Mine and yours: Property rights in dictator games. Journal of Economic Behavior and Organization 65 (3): 703-13.

Pierce, J. L., T. Kostova, and K. T. Dirks. 2001. Toward a theory of psychological ownership in organizations. Academy of Management Review 26 (2): 298-310.

Pierce, J. L., T. Kostova, and K. T. Dirks. 2003. The state of psychological ownership: Integrating and extending a century of research. Review of General Psychology 7(1): 84-107.

Rankin, F., S. Schwartz, and R. Young. 2008. The effect of honesty and superior authority on budget proposals. The Accounting Review 83 (4): 1083-99.

Salterio, S. E., and A. Webb. 2006. Honesty in accounting and control: A discussion of "The Effect of Information Systems on Honesty in Managerial Reporting: A Behavioral Perspective." Contemporary Accounting Research 23 (4): 919-32.

Sansing, R. C. 1993. Information acquisition in a tax compliance game. The Accounting Review 68 (4): 874-84.

Schepers, D. H. 2003. Machiavellianism, profit, and the dimensions of ethical judgment: A study of impact. Journal of Business Ethics 42: 339-52.

Schneider, G. P., J. Dai, D. J. Janvrin, K. Ajayi, and R. L. Raschke. 2015. Infer, predict, and assure: Accounting opportunities in data analytics. Accounting Horizons 29 (3): 71942.

Schwartz, S. H. 1968. Words, deeds and the perception of consequences and responsibility in action situations. Journal of Personality and Social Psychology 10 (3): 232-42.

Schweitzer, M., and C. K. Hsee. 2002. Stretching the truth: Elastic justification and motivated communication of uncertain information. The Journal of Risk and Uncertainty 25 (2): 185-201.

Sen, A. 1997. Maximization and the act of choice. Econometrica 65 (4): 745-80.

Sheremeta, R. M., and T. W. Shields 2013. Do liars believe? Beliefs and other-regarding preferences in sender-receiver games. Journal of Economic Behavior and Organization 94: 268-77.

Shields, M. D., F. J. Deng, and Y. Kato. 2000. The design and effects of control systems: Tests of direct- and indirect-effects models. Accounting, Organizations and Society 25: 185202.

Shu, S. B., and J. Peck. 2011. Psychological ownership and affective reaction: Emotional attachment process variables and the endowment effect. Journal of Consumer Psychology 21 (4): 439-52.

Smith, S. D., W. B. Tayler, and D. F. Prawitt. 2016. The effect of information choice on auditors' judgments and confidence. Accounting Horizons 30 (3): 393-408.

Sprinkle, G. B. 2003. Perspectives on experimental research in managerial accounting. Accounting, Organization and Society 28: 287-318. 
Sutton, S. G., V. Arnold, and M. Holt. 2018. How much automation is too much? Keeping the human relevant in knowledge work. Journal of Emerging Technologies in Accounting (in press).

Tafkov, I., K. Towry, and F. Zhou. 2017. The impact of knowledge transfer on investments in knowledge creation in firms. Working paper.

Trevino, L. K. 1986. Ethical decision making in organizations: A person-situation interactionist model. The Academy of Management Review 11 (3): 601-17.

Van Dyne, L., and J. L. Pierce. 2004. Psychological ownership and feelings of possession: Three field studies predicting employee attitudes and organizational citizenship behavior. Journal of Organizational Behavior 25 (4): 439-59.

Webb, R. A. 2002. The impact of reputation and variance investigations on the creation of budget slack. Accounting, Organizations and Society 27: 361-78.

Zárraga, C., and J. Bonache. 2005. The impact of team atmosphere on knowledge outcomes in self-managed teams. Organization Studies 26 (5): 661-81. 
Figure 1 The Effect of Information Acquisition ${ }^{\mathrm{a}}$ and Reporting Context ${ }^{\mathrm{b}}$ on Average Slack ${ }^{\mathrm{c}}$, Controlling for Machiavellianism ${ }^{\mathrm{d}}$

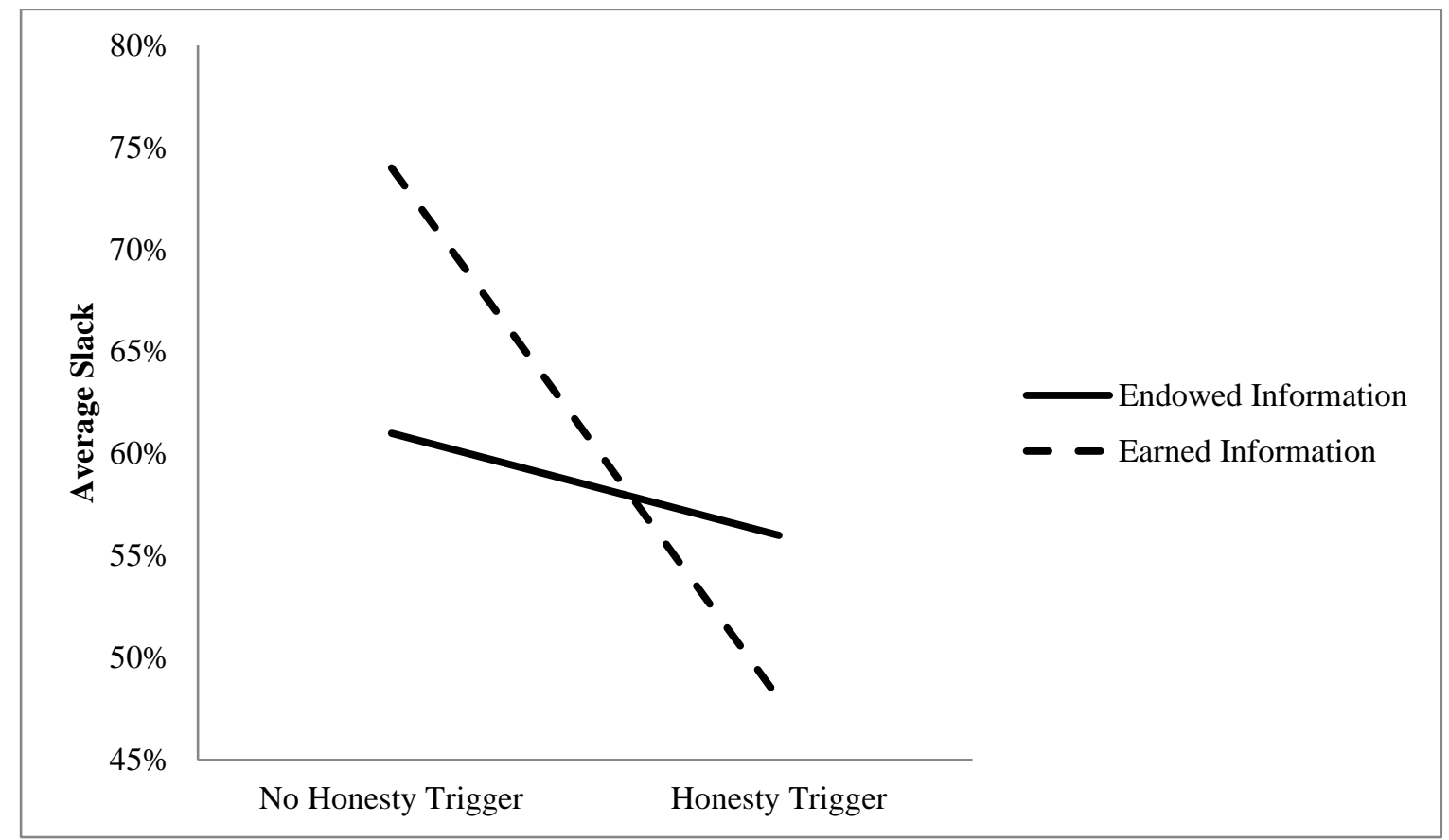

a Information Acquisition is manipulated between subjects. Under the earned information condition, manager-participants could read their private information (the project's cost) from their computer screen in every period. Under the endowed information condition, managers had to exert effort (i.e., solve number series puzzles) to find out this private information.

${ }^{\mathrm{b}}$ Reporting Context is also manipulated on a between-subject basis. Under the no honesty trigger condition, managers reported the share of profit allocated to the owner. Under the honesty trigger condition, they reported the project's cost.

${ }^{\mathrm{c}}$ Average Slack is the ratio of the eight-period mean of slack claimed over slack available. This measure ranges from $0 \%$ to $100 \%$. The higher this ratio, the more opportunistically managers reported.

${ }^{\mathrm{d}}$ Machiavellianism is the mean of four items measured on a Likert scale from 1 (totally disagree) to 7 (totally agree): (1) I tend to manipulate others to get my way, (2) I have used deceit or lied to get my way, (3) I have used flattery to get my way, and (4) I tend to exploit others toward my own end. 
Figure 2 The Effect of Perceived Task Difficulty ${ }^{\mathrm{a}}$, Stress $^{\mathrm{b}}$, and Reporting Context ${ }^{\mathrm{c}}$ on Average Slack ${ }^{\mathrm{d}}$, controlling for Machiavellianism ${ }^{\mathrm{e}}$, within Earned Information Conditions

Panel A: Average Budgetary Slack for Low and High Perceived Task Difficulty

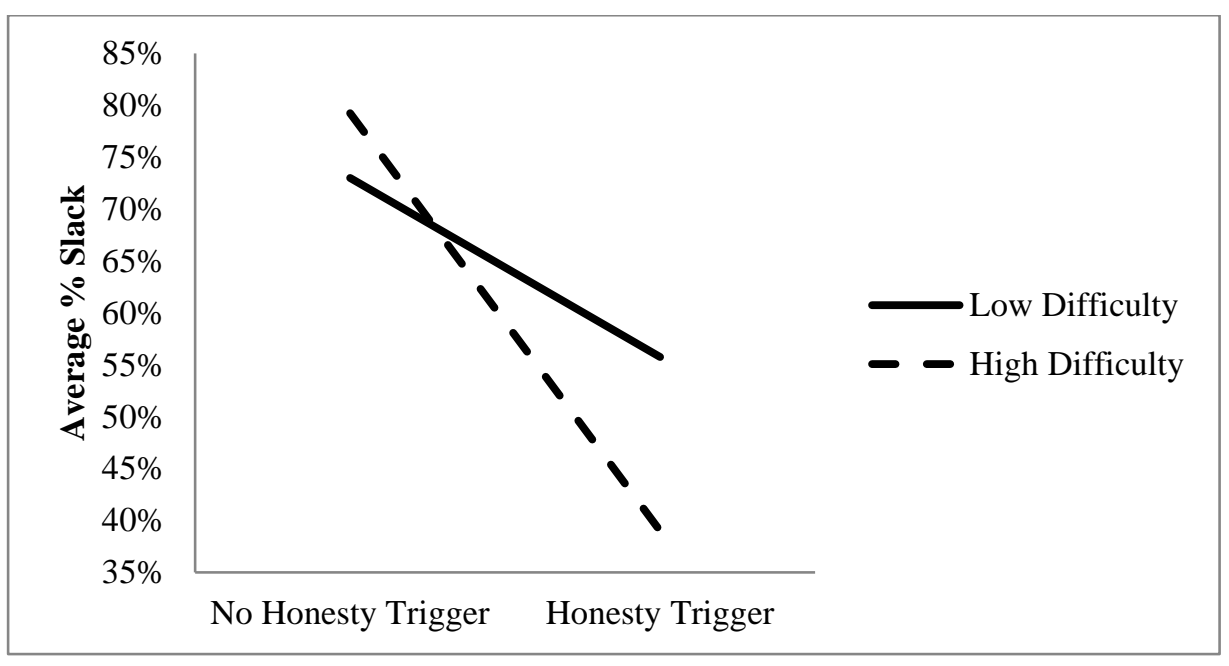

Panel B: Average Budgetary Slack for Low and High Perceived Stress

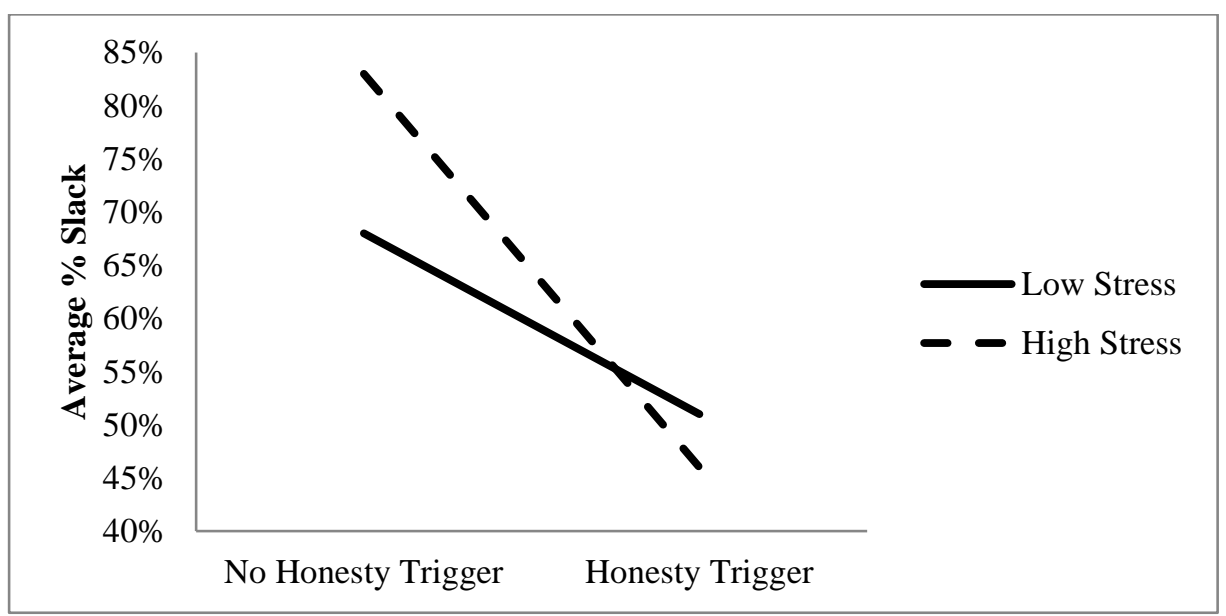

${ }^{a}$ Perceived Task Difficulty comes from the post-experimental questionnaire. Participants indicated on a scale from 1 ("strongly disagree") to 7 ("strongly agree") the extent to which they agreed with the following statement: "Solving these number series puzzles was difficult." A median split divided participants in high- and low-difficulty subsamples.

${ }^{\mathrm{b}}$ Perceived Stress comes from the post-experimental questionnaire. Participants indicated on a scale from 1 ("strongly disagree") to 7 ("strongly agree") the extent to which they agreed with the following statement: "I felt stressed while solving these number series puzzles." A median split divided participants in high- and low-stressed subsamples.

${ }^{\mathrm{c}}$ Reporting Context is manipulated on a between-subject basis. Under the no honesty trigger condition, managers reported the share of profit allocated to the owner. Under the honesty trigger condition, they reported the project's cost.

${ }^{\mathrm{d}}$ Average Slack is the ratio of the eight-period mean of slack claimed over slack available. This measure ranges from $0 \%$ to $100 \%$. The higher this ratio, the more opportunistically managers reported.

${ }^{\mathrm{e}}$ Machiavellianism is the mean of four items measured on a Likert scale from 1 (totally disagree) to 7 (totally agree): (1) I tend to manipulate others to get my way, (2) I have used deceit or lied to get my way, (3) I have used flattery to get my way, and (4) I tend to exploit others toward my own end. 
TABLE 1

Payoff Structure for Managers and Owners across the Reporting Context

\begin{tabular}{|l|c|c|}
\hline & Manager & Owner \\
\hline No honesty trigger & $\begin{array}{c}100+\text { project's total profit }- \text { portion allocated to } \\
\text { owner }\end{array}$ & Portion allocated by manager \\
\hline Honesty trigger & $100+$ reported cost - actual cost & 200 - reported cost \\
\hline
\end{tabular}


TABLE 2

Manager Descriptive Statistics

Panel A: Means and (Standard Deviations), adjusted for Machiavellianism ${ }^{\mathrm{a}}$

No Honesty Trigger

$\begin{array}{lcccc} & \begin{array}{c}\text { Endowed } \\ \text { Information } \\ \mathbf{n = 2 0}\end{array} & \begin{array}{c}\text { Earned } \\ \text { Information } \\ \mathbf{n = 2 1}\end{array} & \begin{array}{c}\text { Endowed } \\ \text { Information } \\ \mathbf{n = 2 0}\end{array} & \begin{array}{c}\text { Earned } \\ \text { Information } \\ \mathbf{n = 2 0}\end{array} \\ \text { Average Slack }^{\mathrm{b}} & 0.61(0.23) & 0.74(0.23) & 0.56(0.24) & 0.48(0.24) \\ \text { Fairness Motivation }^{\mathrm{c}} & 4.10(1.57) & 3.71(1.56) & 3.56(1.61) & 3.70(1.57) \\ \text { Ethical Perception }^{\mathrm{d}} & 3.61(1.65) & 3.61(1.64) & 4.04(1.68) & 4.86(1.65) \\ \text { Machiavellianism } & 3.91(1.17) & 3.56(1.46) & 3.03(0.93) & 3.93(1.25)\end{array}$

Panel B: Pearson Correlation Matrix $(n=81)$

\begin{tabular}{lcccc}
\multicolumn{1}{c}{ Variable } & $\mathbf{1}$ & $\mathbf{2}$ & $\mathbf{3}$ & $\mathbf{4}$ \\
\hline 1 Average Slack & 1 & & & \\
2 Fairness Motivation & $-0.58^{* * *}$ & 1 & 1 & \\
3 Ethical Perception & -0.02 & $-0.19^{*}$ & -0.13 & 1 \\
4 Machiavellianism & $0.30^{* * *}$ & -0.11 &
\end{tabular}

a Machiavellianism is included as a covariate in all my analyses and is the mean of four items measured on a Likert scale from 1 (totally disagree) to 7 (totally agree): (1) I tend to manipulate others to get my way, (2) I have used deceit or lied to get my way, (3) I have used flattery to get my way, and (4) I tend to exploit others toward my own end.

${ }^{\mathrm{b}}$ Average Slack is the ratio of the eight-period mean of slack claimed over slack available. This measure ranges from 0 to1. The higher this ratio, the more opportunistically managers reported.

${ }^{\mathrm{c}}$ Fairness Motivation comes from the post-experimental questionnaire. Participants indicated on a scale from 1 ("strongly disagree") to 7 ("strongly agree") the extent to which they agreed with the following statement: "I wanted to treat the owner fairly."

${ }^{\mathrm{d}}$ Ethical Perception comes from the post-experimental questionnaire. Participants indicated on a scale from 1 ("strongly disagree") to 7 ("strongly agree") the extent to which they agreed with the following statement: "It is unethical to report a cost (honesty trigger condition) / allocate a portion of the profit (no honesty trigger condition) that results in a significantly higher payoff for managers than for owners."

$*, * *, * * *$ Indicate significance at the 10 percent, 5 percent, and 1 percent levels (two-tailed). 
TABLE 3

Main Analyses - Average Slack ${ }^{\mathrm{a}}$

Panel A: ANCOVA for Information Acquisition ${ }^{\mathrm{b}}$, Reporting Context $\mathrm{C}^{\mathrm{c}}$ and Machiavallianism ${ }^{\mathrm{d}}$ on Average Slack

\begin{tabular}{lcccc} 
Factor & df & Mean Square & F & p-value* \\
\hline Information Acquisition (IA) & 1 & 0.02 & 0.27 & 0.61 \\
Reporting Context (RC) & 1 & 0.50 & 9.18 & $<\mathbf{0 . 0 1}$ \\
IA $\times$ RC & 1 & 0.22 & 4.13 & $\mathbf{0 . 0 2}$ \\
Machiavellianism $^{\text {d }}$ & 1 & 0.50 & 9.18 & $<0.01$ \\
Error & 76 & 0.05 & &
\end{tabular}

Panel B: Planned Contrast Analysis

\begin{tabular}{lccccc} 
& Sum of Squares & df & Mean Square & F-statistic & p-value* \\
\cline { 2 - 6 } Contrast $^{\mathrm{e}}$ & 0.690 & 1 & 0.69 & 12.736 & $<0.01$ \\
Residual Variance $^{\mathrm{f}}$ & 0.079 & 2 & 0.04 & 0.731 & 0.48 \\
Machiavellianism & 0.499 & 1 & 0.499 & 9.203 & $<0.01$ \\
Error & 4.12 & 76 & 0.05 & &
\end{tabular}

${ }^{a}$ Average Slack is the ratio of the eight-period mean of slack claimed over slack available. This measure ranges from 0 to 1 . The higher this ratio, the more opportunistically managers reported.

${ }^{\mathrm{b}}$ Information Acquisition is manipulated between subjects. Under the earned information condition, manager-participants could read their private information (the project's cost) from their computer screen in every period. Under the endowed information condition, managers had to perform effort (i.e., solve number series puzzles) to find out this private information.

${ }^{c}$ Reporting Context is also manipulated on a between-subject basis. Under the no honesty trigger condition, managers reported the share of profit allocated to the owner. Under the honesty trigger condition, they reported the project's cost.

${ }^{\mathrm{d}}$ Machiavellianism is the mean of four items measured on a Likert scale from 1 (totally disagree) to 7 (totally agree): (1) I tend to manipulate others to get my way, (2) I have used deceit or lied to get my way, (3) I have used flattery to get my way, and (4) I tend to exploit others toward my own end. ${ }^{\mathrm{e}}$ The model contrast tests whether average slack follows the pattern as follows from the theory. Contrast coefficients are $2,1,-1$, and -2 for the earned information/no honesty trigger, endowed information/no honesty trigger, endowed information/honesty trigger, and earned information/honesty trigger conditions, respectively.

${ }^{\mathrm{f}}$ The residual variance represents the variance that is not explained by the model contrast. The insignificant $\mathrm{p}$-value shows that the model contrast explains all of the between-group variance. * p-values are reported on a two-tailed basis, except the ones in bold, which are reported on a onetailed basis given the directional effects of the hypothesis. 
TABLE 4

Additional Analyses: Planned Contrasts on Average Slack ${ }^{\mathrm{a}}$ within the Earned Information Conditions

Panel A: Low and High Perceived Task Difficulty

Contrast $^{\mathrm{b}}$

Residual Variance ${ }^{\mathrm{c}}$

Machiavellianism $^{\mathrm{d}}$

Error

\begin{tabular}{ccccc} 
Sum of Squares & df & Mean Square & F-statistic & p-value* \\
\hline 0.81 & 1 & 0.81 & 17.37 & $<0.01$ \\
0.04 & 2 & 0.02 & 0.44 & 0.65 \\
0.27 & 1 & 0.27 & 5.66 & 0.02 \\
1.68 & 36 & 0.05 & &
\end{tabular}

Panel B: Low and High Perceived Stress

\begin{tabular}{lccccc} 
& Sum of Squares & df & Mean Square & F-statistic & p-value* \\
\cline { 2 - 6 } Contrast $^{\mathrm{e}}$ & 0.81 & 1 & 0.81 & 16.91 & $<0.01$ \\
Residual Variance $^{\mathrm{c}}$ & 0.01 & 2 & 0.01 & 0.13 & 0.88 \\
Machiavellianism & 0.28 & 1 & 0.28 & 5.76 & 0.02 \\
Error & 1.72 & 36 & 0.05 & &
\end{tabular}

${ }^{a}$ Average Slack is the ratio of the eight-period mean of slack claimed over slack available. This measure ranges from 0 to 1 . The higher this ratio, the more opportunistically managers reported. ${ }^{\mathrm{b}}$ The model contrast tests whether average slack follows the pattern as follows from the theory. Contrast coefficients are $2,1,-1$, and -2 for the high task difficulty/no honesty trigger, low task difficulty/no honesty trigger, low task difficulty/honesty trigger, and high task difficulty/honesty trigger conditions, respectively.

${ }^{\mathrm{c}}$ The residual variance represents the variance that is not explained by the model contrast. The insignificant p-value shows that the model contrast explains all of the between-group variance.

${ }^{\mathrm{d}}$ Machiavellianism is the mean of four items measured on a Likert scale from 1 (totally disagree) to 7 (totally agree): (1) I tend to manipulate others to get my way, (2) I have used deceit or lied to get my way, (3) I have used flattery to get my way, and (4) I tend to exploit others toward my own end. ${ }^{\mathrm{e}}$ The model contrast tests whether average slack follows the pattern as follows from the theory. Contrast coefficients are $2,1,-1$, and -2 for the high stress/no honesty trigger, low stress/no honesty trigger, low stress/honesty trigger, and high stress/honesty trigger conditions, respectively.

* p-values are reported on a two-tailed basis. 